\section{BMJ Open Respiratory Research}

\title{
Training opportunities in thoracic ultrasound for respiratory trainees: are current guidelines practical?
}

Andrew E Stanton (D) , ${ }^{1}$ Matthew Evison (D) , ${ }^{2,3}$ Mark Roberts, ${ }^{4,5}$ Jennifer Latham, ${ }^{6}$ Amelia O Clive, ${ }^{7}$ Elizabeth Batalla-Duran, ${ }^{8}$ Rahul Bhatnagar, ${ }^{9}$ Rachelle Asciak, ${ }^{10}$ Ben Diggins, ${ }^{11}$ Oliver J Bintcliffe, ${ }^{12}$ Diana Lees, ${ }^{13}$ Maria Parsonage, ${ }^{14}$ Peppa Denny, ${ }^{15}$ Kathryn Gow, ${ }^{16}$ Cristina Avram, ${ }^{17}$ Manish Gautam, ${ }^{18}$ Najib M Rahman ${ }^{19}$

To cite: Stanton AE, Evison M, Roberts M, et al. Training opportunities in thoracic ultrasound for respiratory trainees: are current guidelines practical?. BMJ Open Resp Res 2019;6:e000390. doi:10.1136/ bmjresp-2018-000390

Received 14 December 2018 Revised 6 May 2019 Accepted 10 August 2019

\section{Check for updates}

(c) Author(s) (or their employer(s)) 2019. Re-use permitted under CC BY-NC. No commercial re-use. See rights and permissions. Published by BMJ.

For numbered affiliations see end of article.

Correspondence to Dr Andrew E Stanton, Department of Respiratory Medicine, Great Western Hospitals NHS Foundation Trust, Swindon, Swindon, UK andrew.stanton@nhs.net

\section{ABSTRACT}

Introduction Respiratory trainees in the UK face challenges in meeting current Royal College of Radiologists (RCR) Level 1 training requirements for thoracic ultrasound (TUS) competence, specified as attending 'at least one session per week over a period of no less than 3 months, with approximately five scans per session performed by the trainee (under supervision of an experienced practitioner)'. We aimed to clarify where TUS training opportunities currently exist for respiratory registrars. Methods Data were collected (over a 4-week period) to clarify the number of scans (and therefore volume of training opportunities) within radiology departments and respiratory services in hospitals in the South West, North West deaneries and 0xford.

Results 14 hospitals (including three tertiary pleural centres) provided data. Of 964 scans, 793 (82.3\%) were conducted by respiratory teams who performed a mean of 17.7 scans per week, versus 3.1 TUS/week in radiology departments. There was no radiology session in any hospital with $\geq 5$ TUS performed, whereas $8 / 14$ (86\%) of respiratory departments conducted such sessions. Almost half $(6 / 14)$ of radiology departments conducted no TUS scans in the period surveyed.

Conclusions The currently recommended exposure of regularly attending a list or session to undertake five TUS is not achievable in radiology departments. The greatest volume of training opportunities exists within respiratory departments in a variety of scheduled and unscheduled settings. Revision of the competency framework in TUS, and where this is delivered, is required.

\section{INTRODUCTION}

Respiratory medicine trainees in the UK are expected to obtain competency in thoracic ultrasound (TUS), specified as 'focused level 1 competent' within the existing curriculum. ${ }^{12}$ Many trainees will however wish to gain the broader level of competence described in the Royal College of Radiologists (RCR) guidelines by obtaining full 'level 1 competence' in TUS. Within this framework there is a clear description

\section{Key messages}

\section{What is the key question?}

- Can trainees in respiratory medicine in the UK expect to achieve the level of training required by Royal College of Radiologists guidelines in the sessional manner required within radiology departments and if not where do these opportunities exist?

What is the bottom line?

- The overwhelming majority of thoracic ultrasound scans are being conducted by respiratory rather than radiology teams and no radiology department surveyed over a total of 55 weeks across 14 hospitals conducted the currently required five scans in any session.

Why read on?

- Further debate and revision around the competency framework for thoracic ultrasound for respiratory trainees in the UK is required and informed by this data.

of the level of training required as 'at least one session per week over a period of no less than 3 months, with approximately five scans per session performed by the trainee (under supervision of an experienced practitioner) '. ${ }^{3}$ With the increasing development of physician led TUS within both tertiary and secondary settings, there is concern among trainees and trainers that the majority of TUS training opportunities in the UK are not sessional as stipulated in the guidelines and also that the training standards fail to take account of differential attainment of learning by individuals. We aimed to clarify where TUS training opportunities currently exist for respiratory registrars within a variety of training environments. 


\section{METHODS}

Trainees in the South West deanery were contacted in early 2017 through a well-established group e-mail distribution list, with requests for data later extended to the North West (through North West Pleural network) and Oxford. Hospitals were invited to submit data regarding the number of TUS scans performed within the radiology and respiratory departments over any 4-week period between January and May 2017. Data could be collected retrospectively or prospectively. Radiology data were collected through interrogation of electronic records/ appointment systems. For TUS performed by radiology departments, we sought to establish the numbers of scans per morning/afternoon session, for each week of data collection. Respiratory data were collected by one individual within each trust (registrar, consultant or nurse consultant) by interrogation of ultrasound machines, review of clinic/procedural lists. Detail was sought as to circumstances of the scans, that is, from a pleural clinic, procedure list or being performed on an ad hoc basis in the respiratory/other ward or clinic. Data submitted represented the total number of scans performed within each hospital (and therefore 'total opportunities' in theory available to trainees), not the number of scans done by one individual within the department. If accurate numbers of scans in any location for any week was not available respondents were asked to estimate numbers (either $0,1-5,6-10$ or $>10$ scans) within such sessions.

\section{PATIENT AND PUBLIC INVOLVEMENT}

There was no specific patient or public involvement in this study.

\section{RESULTS}

Data were provided from 14 hospitals (six South West, seven North West, one Oxford) including three tertiary pleural centres (Oxford, Bristol (Southmead) and South Manchester). Respiratory results from two centres represent estimated numbers and one site (North Manchester) submitted only 3 weeks data.

The majority of TUS scans were performed within respiratory departments. Of 964 scans, 793 (82.3\%) were conducted by respiratory teams who performed a mean of 17.7 scans per week, versus 3.1 TUS/week in radiology departments (figure 1). The breakdown of the various sessions and contexts where respiratory TUS was performed is shown in table 1 , alongside sessional radiology numbers. Six of the 14 radiology departments conducted no TUS scans at all in this period. There was not a single radiology session in any hospital with $\geq 5$ thoracic ultrasound scans performed (out of total of 55 weeks sampled across all sites) which is the requirement for RCR training. In contrast, 8/14 (86\%) of respiratory departments conducted sessions with $\geq 5$ TUS scans.

\section{DISCUSSION}

This is the first piece of work to date which directly addresses current training opportunities in TUS in the

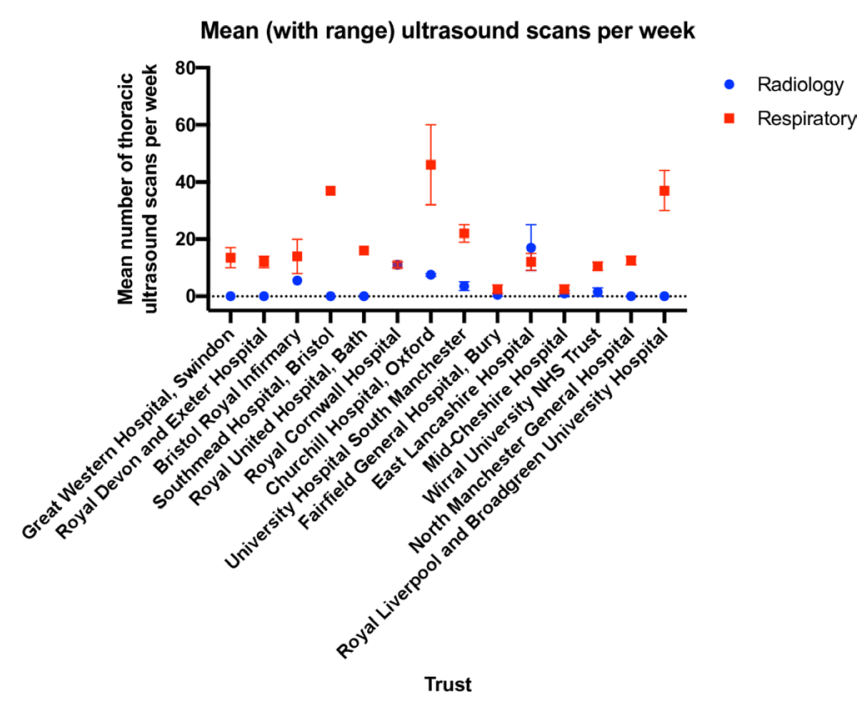

Figure 1 Mean number of ultrasound scans each week in radiology and respiratory departments.

UK. A recent published survey of 202 respiratory trainees (approximately one third of all trainees nationally) confirmed there is concern about access to radiologists for training (only clearly possible in $18.9 \%$ of respondents) and also competent ultrasonographer review of difficult cases (not easy or impossible in approximately $30 \%) .{ }^{4}$ Of concern, this survey also suggested that even in those with level 1 competence there is a lack of confidence in performing pleural procedures based on the trainees personal ultrasound assessment, suggesting the current framework is failing to adequately prepare trainees for independent practice.

Trainees currently find themselves in a difficult position. Although the formal training requirement is that competence in 'focused thoracic ultrasound' is obtained by the end of ST5, many will wish to obtain the higher level 'level 1 RCR competency'. The Focused TUS guidance was produced (by radiologists) to target training of individuals who may wish to use ultrasound to only guide drainage of pleural effusions. ${ }^{2}$ Clearly this skill has its place but this competency as described fails to cater for the complexity of pleural decision making required in both the acute and outpatient settings that the majority of respiratory trainees need training and demonstrable competence in. In the longer term, trainees may also wish to potentially become the trainer, which one can only do as an RCR level 1 practitioner with 2 years experience. The Focused TUS guidance gives no framework for competent practitioners to legitimately train or supervise other learners. Although the knowledge base described for RCR level 1 and Focused are identical, there is a distinct difference in the description of practical training requirements. Focused TUS requires trainees to perform a total of 80 scans (20 observed, 20 normals, 20 effusions and 20 interventions) all with supervision of an experienced operator (such as a radiologist) and Level 1 RCR competency does indicate a clear requirement for a weekly sessional training over a 3-month period. 


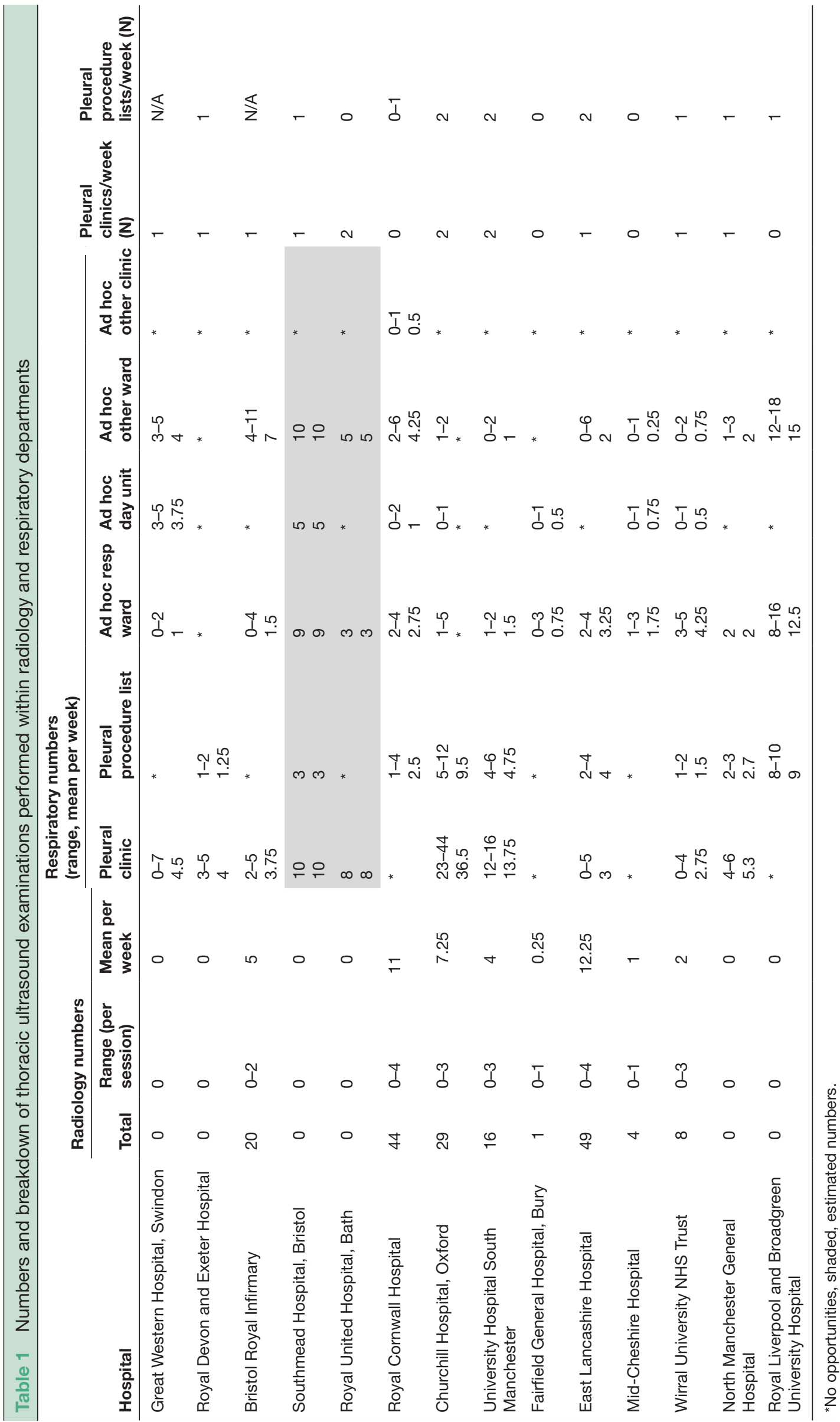


Our data demonstrate that it is highly unlikely that a trainee will gain sufficient exposure in the sessional manner required for level one TUS competence in radiology departments in the UK, especially considering almost half of departments surveyed performed no TUS scans in the period surveyed. We have however, shown that adequate learning opportunities exist within respiratory teams in both tertiary and district general settings and that respiratory physicians are delivering the vast majority of thoracic ultrasound work in the UK at present. Although current guidelines do not mandate training within radiology departments, they do stipulate a sessional requirement and we have demonstrated the varied settings within respiratory practice throughout the working week where opportunities exist. There seems little justification for insisting on a sessional nature to TUS training as even within respiratory medicine this could only be delivered in selected pleural clinic/procedure lists in larger tertiary units. The unscheduled nature of pleural disease presentation needs to be recognised in planning training requirements.

We have not indicated the number of trainees within each institution who would have access to these opportunities and while it is still possible for smaller hospitals to struggle to provide large volume of respiratory departmental opportunities in ultrasound training, it is highly unlikely that radiology departments in these smaller units will be providing an alternative experience. Trainees are not necessarily expected to complete Focused/level 1 RCR TUS training within only one institution however, and it is clear that relevant training opportunities exist in district hospital settings as well as larger centres, even where a 'sessional' opportunity is not available.

Data were collected by individuals working within respiratory teams and so will not take account of any scans undertaken by non-respiratory teams using non-respiratory equipment (eg, emergency department/acute physicians). It is possible therefore numbers performed out with radiology may be an underestimate but we feel this is unlikely to be a significant issue as non-respiratory performed ward-based TUS is not commonly undertaken in the hospitals surveyed. Only two trusts supplied estimated respiratory data in this respect.

In the context of the demonstrable difficulties in achieving the current training requirements, this data suggest that current guidelines need to be reviewed to take account of where learning opportunities exist, in both scheduled and unscheduled circumstances. The validity of 'ad hoc' training opportunities needs to be recognised, as this is not the case presently. One could argue that more frequent small volume learning opportunities actually give greater opportunity for reflection, practice improvement and so forth (as well described in Kolb's learning cycle) and so may actually enhance learning in comparison to sessional exposure (with minimal specific TUS opportunity). It is the responsibility of trainers to provide a supportive learning environment with regular and detailed feedback, time for reflection and discussion. If all of this is done within a competency framework that includes appropriately valid methods of assessment then there is no reason to assume opportunistic exposure to learning is inadequate.

Finally there is an opportunity for training guidelines to move away from a competency based framework that is perceived as 'numbers' based to one which takes account of the varied and complex pleural ultrasound work undertaken by respiratory physicians, recognises that trainees will learn (and demonstrate 'competence') at different rates and ultimately is a framework based on educational best practice. Moving towards development of a 'competency in practice' model of training and assessment in thoracic ultrasound, which would be aligned with developments in the new internal medicine curriculum, ${ }^{5}$ should be considered.

\section{Author affiliations}

${ }^{1}$ Department of Respiratory Medicine, Great Western Hospitals NHS

Foundation Trust, Swindon, , UK

${ }^{2}$ North West Lung Centre, University Hospital South Manchester, Manchester, UK

${ }^{3}$ Institute of Inflammation and Repair, University of Manchester, Manchester, UK

${ }^{4}$ Respiratory Medicine, Sherwood Forest Hospitals NHS Foundation Trust, Sutton-In-Ashfield, , UK

${ }^{5} U K$

${ }^{6}$ Respiratory, Raigmore Hospital, Inverness, UK

${ }^{7}$ Department of Respiratory Medicine, Bristol Royal Infirmary, Bristol, UK

${ }^{8}$ Department of Respiratory Medicine, Royal Devon and Exeter Hospital, Exeter, UK

${ }^{9}$ Academic Respiratory Unit, University of Bristol, Bristol, UK

${ }^{10}$ Department of Respiratory Medicine, Churchill Hospital, Oxford, UK

${ }^{11}$ Department of Respiratory Medicine, Royal Cornwall Hospital, Truro, UK

${ }^{12}$ Department of Respiratory Medicine, Royal United Hospitals Bath NHS Foundation Trust, Bath, UK

${ }^{13}$ Department of Respiratory Medicine, Mid-Cheshire Hospitals NHS Foundation Trust, Crewe, UK

${ }^{14}$ Department of Respiratory Medicine, Wirral University Teaching Hospitals NHS Foundation Trust, Wirral, UK

${ }^{15}$ Department of Respiratory Medicine, East Lancashire Hospitals NHS Trust, Blackburn, UK

${ }^{16}$ Department of Respiratory Medicine, Fairfield General Hospital, Bury, UK

${ }^{17}$ Department of Respiratory Medicine, North Manchester General Hospital, Manchester, UK

${ }^{18}$ Department of Respiratory Medicine, Royal Liverpool and Broadgreen University Hospital, Liverpool, UK

${ }^{19}$ Oxford Centre for Respiratory Medicine, Oxford University Hospitals NHS Trust, Oxford, UK

Contributors AS had the original idea for the project. ME and NMR facilitated data contribution from Oxford and North West deaneries. Data from individual sites were collected and submitted by AS, ME, MR, EB-D, RB, RA, BD, OJB, DL, MP, PD, KG,

$C A$ and $M G$. AS drafted the manuscript which received further contributions from $\mathrm{ME}, \mathrm{MR}, \mathrm{AOC}$, JL and NMR. All authors then reviewed and contributed to the final manuscript.

Funding The authors have not declared a specific grant for this research from any funding agency in the public, commercial or not-for-profit sectors.

Competing interests None declared.

Patient consent for publication Not required.

Provenance and peer review Not commissioned; externally peer reviewed.

Data availability statement All data relevant to the study are included in the article or uploaded as supplementary information.

Open access This is an open access article distributed in accordance with the Creative Commons Attribution Non Commercial (CC BY-NC 4.0) license, which 
permits others to distribute, remix, adapt, build upon this work non-commercially, and license their derivative works on different terms, provided the original work is properly cited, appropriate credit is given, any changes made indicated, and the use is non-commercial. See: http://creativecommons.org/licenses/by-nc/4.0/.

ORCID iDs

Andrew E Stanton http://orcid.org/0000-0001-6758-7051

Matthew Evison http://orcid.org/0000-0003-4066-5253

\section{REFERENCES}

1 Joint Royal College of Physicians Training Board. Speciality training curriculum in respiratory medicine (Ammendments 2014). London, 2010.

2 Royal College of Radiologists. Focused ultrasound training standards. London: The Royal College of Radiologists, 2012.

3 Royal College of Radiologists. Ultrasound training recommendations for medical and surgical Specialities. 3rd edn. London: The Royal College of Radiologists, 2017.

4 Sivakumar P, Kamalanathan M, Collett AS, et al. Thoracic ultrasound experiences among respiratory specialty trainees in the UK. Clin Med 2017;17:408-11.

5 JRCPTB. Curriculum for internal medicine stage 1 training. JRCPTB, 2018. 